University of Nebraska - Lincoln

DigitalCommons@University of Nebraska - Lincoln

NASA Publications

National Aeronautics and Space Administration

2011

Mass flux at ignition in reduced pressure environments

Sonia Fereres

University of California, Berkeley, sfereres@berkeley.edu

Chris Lautenberger

University of California, Berkeley,

Carlos Fernandez-Pello

University of California, Berkeley

David Urban

NASA John H. Glenn Research Center, Cleveland, $\mathrm{OH}$

Gary Ruff

NASA John H. Glenn Research Center, Cleveland, $\mathrm{OH}$

Follow this and additional works at: https://digitalcommons.unl.edu/nasapub

Part of the Physical Sciences and Mathematics Commons

Fereres, Sonia; Lautenberger, Chris; Fernandez-Pello, Carlos; Urban, David; and Ruff, Gary, "Mass flux at ignition in reduced pressure environments" (2011). NASA Publications. 53.

https://digitalcommons.unl.edu/nasapub/53

This Article is brought to you for free and open access by the National Aeronautics and Space Administration at DigitalCommons@University of Nebraska - Lincoln. It has been accepted for inclusion in NASA Publications by an authorized administrator of DigitalCommons@University of Nebraska - Lincoln. 


\title{
Mass flux at ignition in reduced pressure environments
}

\author{
Sonia Fereres ${ }^{\mathrm{a}, *}$, Chris Lautenberger ${ }^{\mathrm{a}}$, Carlos Fernandez-Pello ${ }^{\mathrm{a}}$, David Urban ${ }^{\mathrm{b}}$, Gary Ruff ${ }^{\mathrm{b}}$ \\ ${ }^{a}$ Department of Mechanical Engineering, University of California, Berkeley, CA 94720, USA \\ ${ }^{\mathrm{b}}$ NASA John H. Glenn Research Center, Cleveland, $\mathrm{OH} 44135$, USA
}

\section{A R T I C L E I N F O}

\section{Article history:}

Received 8 September 2010

Received in revised form 18 November 2010

Accepted 25 November 2010

Available online 5 January 2011

\section{Keywords:}

Mass loss

Mass flux at ignition

Ignition delay time

Low pressure

\begin{abstract}
A B S T R A C $T$
Ignition of solid combustible materials can occur at atmospheric pressures lower than standard either in high altitude environments or inside pressurized vehicles such as aircraft and spacecraft. NASA's latest space exploration vehicles have a cabin atmosphere of reduced pressure and increased oxygen concentration. Recent piloted ignition experiments indicate that ignition times are reduced under these environmental conditions compared to normal atmospheric conditions, suggesting that the critical mass flux at ignition may also be reduced. Both effects may result in an increased fire risk of combustible solid materials in reduced pressure environments that warrant further investigation. As a result, a series of experiments are conducted to explicitly measure fuel mass flux at ignition and ignition delay time as a function of ambient pressure for the piloted ignition of PMMA under external radiant heating. Experimental findings reveal that ignition time and the fuel mass flux at ignition decrease when ambient pressure is lowered, proving with the latter what earlier authors had inferred. It is concluded that the reduced pressure environment results in smaller convective heat losses from the heated material to the surroundings, allowing for the material to heat more rapidly and pyrolyze faster. It is also proposed that a lower mass flux of volatiles is required to reach the lean flammability limit of the gases near the pilot at reduced pressures, due mainly to a reduced oxygen concentration, an enlarged boundary layer, and a thicker fuel species profile.
\end{abstract}

(C) 2010 The Combustion Institute. Published by Elsevier Inc. All rights reserved.

\section{Introduction}

Fires can occur in lower than standard atmospheric pressure either in natural high altitude environments or inside pressurized vehicles such as aircraft and spacecraft. Ambient pressures at high altitude locations such as Lhasa, a city in Qinghai-Tibet Plateau at approximately $3650 \mathrm{~m}$ above sea level are about $67 \mathrm{kPa}$, which is $34 \%$ lower than standard atmosphere (101 kPa, 21\% $\mathrm{O}_{2}$ ). Typically aircraft cabin air is pressurized to an equivalent "cabin altitude" between 1500 and $2400 \mathrm{~m}$ (84-75 kPa) following FAA regulations [1] to enable passenger comfort while minimizing the fuselage structure fatigue. Furthermore, the cabin environment of NASA's latest generation of spacecraft (Orion Crew Exploration Vehicle, Altair Lunar Lander) and future lunar habitats has lower pressures and increased oxygen concentrations $\left(55-70 \mathrm{kPa}, 27-32 \% \mathrm{O}_{2}\right)$ than standard atmosphere [2]. These new environment conditions present several advantages, such as lower internal vehicle pressures, a reduced risk of decompression sickness during extra-vehicular activities (EVA) and shorter pre-breathing times required for EVA preparation. However, they may increase material flammability due to higher flame temperatures (attributed to enhanced oxygen)

\footnotetext{
* Corresponding author. Fax: +1510642 1850.

E-mail address: sfereres@berkeley.edu (S. Fereres).
}

and reduced convective heat losses from heated surfaces (attributed to reduced pressure). They may also affect gas phase processes related to material flammability such as time to reach a flammable mixture in the gas, and the gaseous mixture ignition induction time. These effects may have potential consequences in the evaluation of the fire risk of materials under low pressure environmental conditions and consequently warrant attention.

Experiments conducted in Lhasa on the spontaneous ignition of wood [3] have shown a considerable reduction in ignition delay time when compared to similar experiments at standard atmosphere. Recent work [4,5] on piloted ignition of PMMA show that ignition delay times decrease under low pressure and high oxygen concentration. Additional studies performed with aerospace materials [6] determined the flammability pressure thresholds, i.e. maximum pressure in which the sample would self extinguish in $99.8 \%$ $\mathrm{O}_{2}$ environments to be between 2.7 and $6.2 \mathrm{kPa}$. The mechanisms responsible for these trends are not entirely understood. However, since piloted ignition is associated with reaching a critical mass flux from the fuel surface [7-9], it has been hypothesized that the reduction in ignition time with decreasing pressure is mainly due to two effects: firstly, a decrease in the heat transfer coefficient that reduces the heat losses from the solid fuel to its surroundings, leading to a faster solid heating process, and secondly, a decrease in the mass flux from the fuel surface necessary to generate a flammable mixture near the igniter [4,5]. 
Although the critical mass flux at ignition has been previously measured at ambient pressures for a range of oxygen concentrations and variable external heat fluxes [9], we are not aware of any experiments where mass loss rates at ignition were measured under reduced atmospheric pressure conditions. Therefore, the objective of the present work is to measure the fuel mass flux at ignition in reduced pressures to verify experimentally the mechanisms leading to the reduction of the piloted ignition delay with pressure.

\section{Description of experiments}

Measuring the mass flux at ignition with accuracy is notoriously difficult [10] primarily because the mass change is small. Consequently, its measurement requires precise instrumentation and a laboratory setting free from external vibrations. The approach followed here for the experiments is similar to that of Ref. [9] but with the experiments performed in a controlled-atmosphere version of the Forced-flow Ignition and flame Spread Test (FIST) apparatus [11]. Figure. 1 shows a simplified schematic of the apparatus. It consists of a small-scale combustion wind tunnel and supporting instrumentation that is mounted horizontally in a sealed pressure vessel (Fig. 2) that allows tests to be performed at varied ambient pressures. The tunnel is $39.2 \mathrm{~cm}$ long in the streamwise direction, $14.9 \mathrm{~cm}$ wide, and $8 \mathrm{~cm}$ high. A fan at the downstream end of the tunnel induces a forced-flow of oxidizer through the tunnel that is recirculated inside the pressure vessel. Solid fuel samples, $3 \mathrm{~cm}$ by $3 \mathrm{~cm}$ by $1 \mathrm{~cm}$ thick, are mounted in the bottom wall of the flow tunnel and are irradiated with a uniform heat flux by an infrared radiant heater mounted directly above the sample. Piloted ignition is induced with an electrically heated 3-mm diameter coiled Kanthal wire mounted $10 \mathrm{~mm}$ downstream of the sample and centered $5 \mathrm{~mm}$ above the tunnel wall. The igniter temperature is kept above $1000{ }^{\circ} \mathrm{C}$ in all tests. The chamber pressure is varied between $7 \mathrm{kPa}$ and $100 \mathrm{kPa}$ and is monitored using a pressure transducer. For the tests reported here, air was used as oxidizer.

To measure the fuel mass loss, the solid fuel sample is placed inside an aluminum sample holder insulated with Cotronics ceramic paper ( $2 \mathrm{~mm}$ thick) on the sides and Cotronics insulating board (RESCOR-360H, $28 \mathrm{~mm}$ thick) on the bottom. The weight of the sample/holder unit is measured continuously with a Sartorius WZ214S data logging scale with $0.1 \mathrm{mg}$ resolution that is positioned below the sample holder. Because the mass loss rate is very small, the measurements are sensitive to external effects such as variations in the gas flow over the sample, room vibrations, etc. To reduce the potential error introduced by these effects, four tests are conducted for each data point and the values averaged. All the tests are conducted with commercially available black PMMA (Atoglas Type $G$ ). The selection of black PMMA was made to have a material with an emissivity close to unity.

One K-type thermocouple was mounted on the top surface of the sample. Although care was taken to ensure that the thermo-

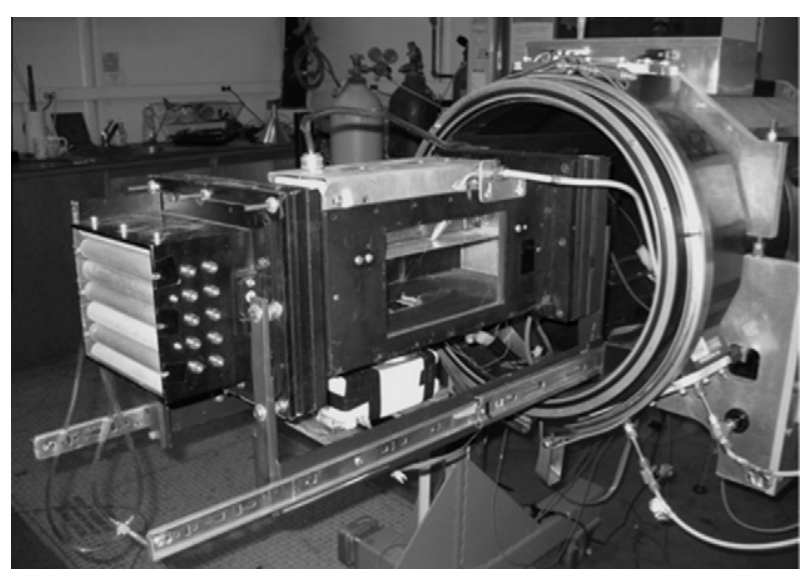

Fig. 2. FIST tunnel and containment chamber.

couple bead was embedded flush with the sample surface, the measured temperature is only an approximation of the actual surface temperature due to potential movement of the thermocouple during heating of the material. However, these inaccuracies are not sufficiently large to affect the trends observed in the experiments presented below.

To perform a test, the fan is turned on and the flow is allowed to reach a steady state. The infrared radiant heater is then turned on to heat the sample, and the igniter is energized after the measured surface temperature reaches $280^{\circ} \mathrm{C}$. The pyrolyzed vapors leave the surface of the solid fuel and convect and diffuse downstream toward the igniter, where the pyrolyzate/air mixture may ignite if the conditions are appropriate.

The ignition time is measured as the elapsed time between initiation of the external heat flux and permanent attachment of a diffusion flame at the sample surface (burning). Time to ignition is judged visually and confirmed by inspection of surface thermocouple temperature traces and changes in the mass loss.

\section{Experimental results}

Piloted ignition tests were performed with an applied radiant heat flux of $16 \mathrm{~kW} / \mathrm{m}^{2}$ and a forced air flow of $0.4 \mathrm{~m} / \mathrm{s}$, for ambient pressures ranging from 7 to $100 \mathrm{kPa}$. Sample surface temperature and sample mass were recorded until ignition was observed. The fuel mass flux at ignition is calculated as the slope of the mass loss time history data during the $5 \mathrm{~s}$ window prior to the observed ignition.

Visual observation of the fuel sample surface and flame characteristics give a first indication of the significant influence that ambient pressure has on the mechanisms leading to the ignition of PMMA and on the characteristics of gas above the sample surface. Figure. 3 shows photographs of two tests, one at $21 \mathrm{kPa}$

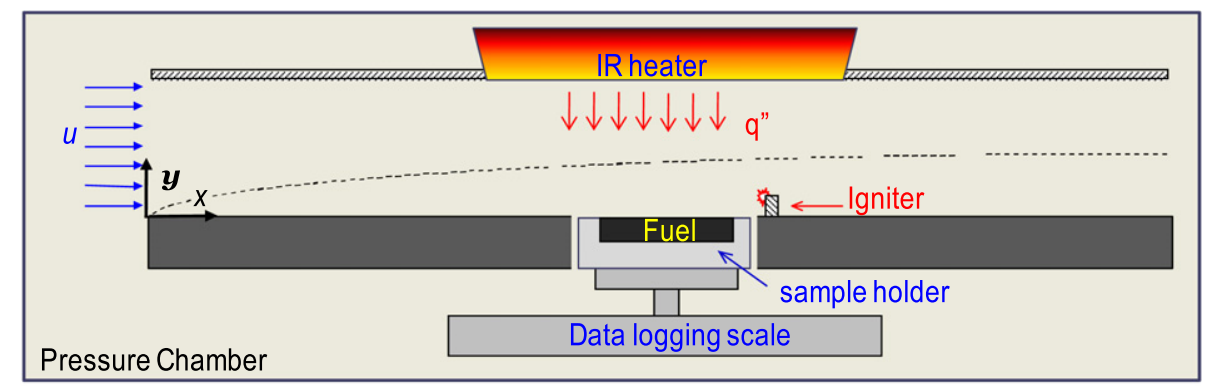

Fig. 1. Simplified schematic of FIST tunnel. 

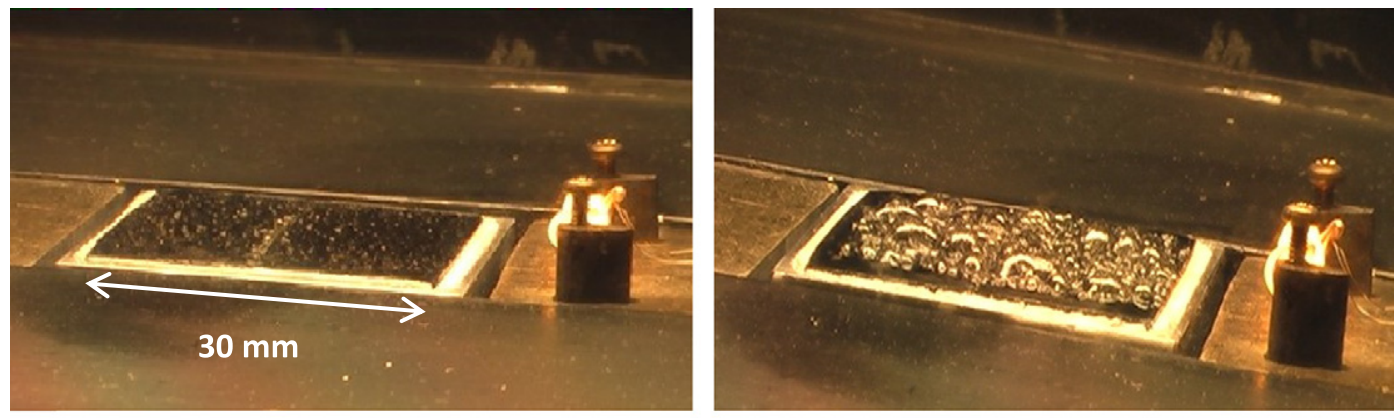

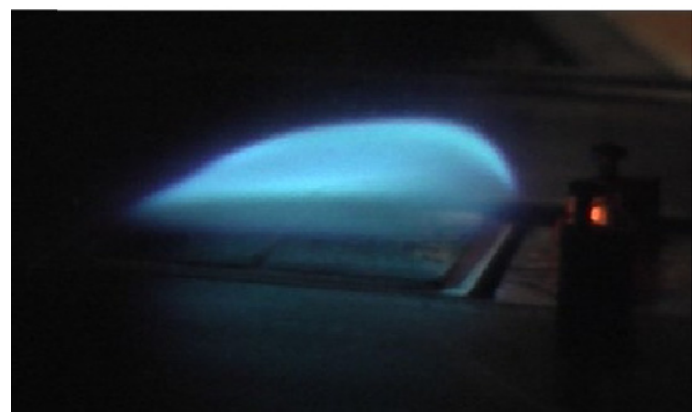

(a) $21 \mathrm{kPa}$

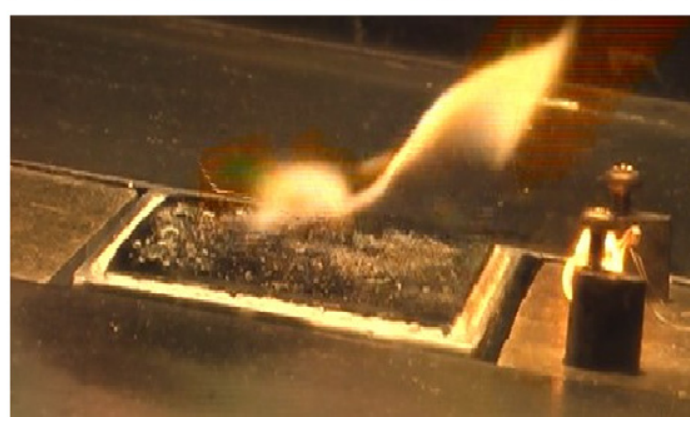

(b) $83 \mathrm{kPa}$

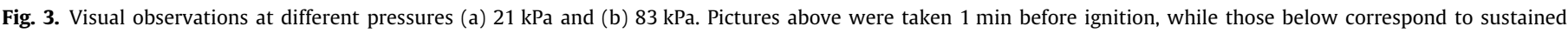
burning of the solid fuel.

(a) and one at $83 \mathrm{kPa}$ (b). The images in Fig. 3 (top row) were taken during the heating process, approximately at one minute before ignition. The surface behavior changed significantly depending on the ambient pressure. At lower pressures the bubble formation that takes place during the pyrolysis of the PMMA occurred earlier, the size of the bubbles was considerably smaller and the bursting of the bubbles occurred in a less violent manner. The characteristics of the flame that is established over the solid surface after ignition is also notable different (Fig. 3 - bottom row). At low pressure the flame is bluer, of rounder shape and more separated from the solid surface than at standard pressure. These visual observations indicate that the effect of pressure on the ignition of solid combustibles may be complex, affecting the heating of the solid, its pyrolysis or gasification process, and the characteristics of the gas above the solid surface.

The data from the surface thermocouple and the load cell are used to obtain histories of surface temperature and sample mass loss, respectively. Figure. 4 compares measured surface temperature and mass loss for four representative experiments performed at ambient pressures of $21,55,83$ and $100 \mathrm{kPa}$. The top curves correspond to the sample mass loss and the lower curves to surface temperatures. Time zero corresponds to the application of the external heat flux and the sudden change in slope in both temperature and mass loss corresponds to the onset of ignition. It can be seen that the ignition time decreases considerably as ambient pressure is reduced, which confirms previous results in complementary work by the authors $[4,5]$. These four tests show a clear difference in the surface temperature and mass loss histories with pressure. As the pressure is reduced, the surface temperature and mass loss increase faster. The differences in the traces reveal the influence of pressure on the sample heating. The fluctuations in the measured surface temperature appear to be the result of movements of the thermocouple bead due to the PMMA melting and the bubbling during pyrolysis that as indicated above is more intense at increased pressure. The surface temperature at ignition is slightly higher at lower pressures. The mass loss traces show that the cumulative mass loss prior to ignition decreases as pressure

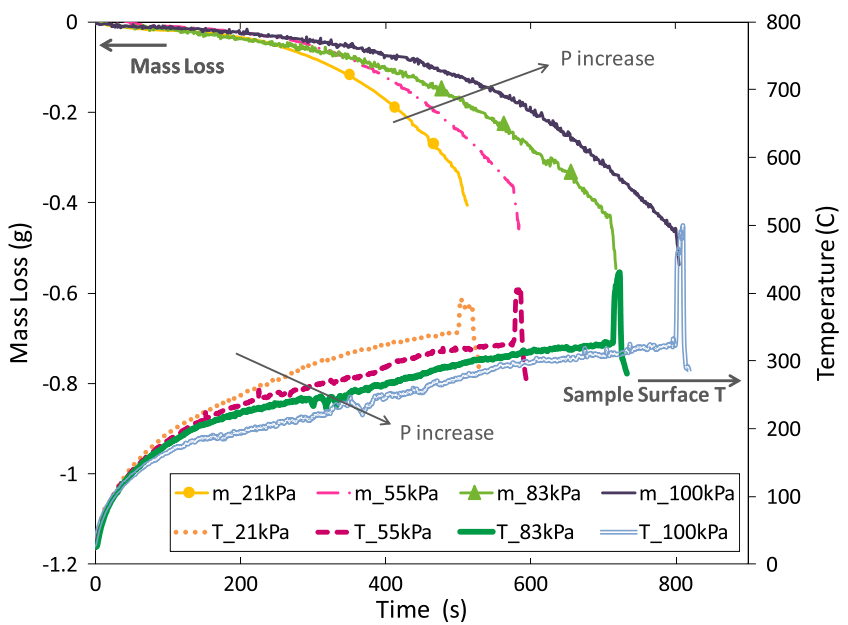

Fig. 4. Comparison of four ignition delay tests at different ambient pressures. Top curves represent sample mass loss and the bottom curves sample surface temperature.

is reduced. This is a novel observation that may have notable implications in material flammability issues. Data similar to that presented in Fig. 4 are used to calculate the variation with pressure of the time to ignition, the total mass lost at ignition, and the mass flux at ignition.

Fig. 5 shows the measured variation of the ignition delay time $\left(t_{i g}\right)$ with pressure. For the range of pressures tested the ignition time decreases linearly with ambient pressure as: $t_{i g}=4.57 \cdot P+$ 358.51 ( $t_{\text {ig }}$ in s and $P$ in $\mathrm{kPa}$ ). Ignition was not attained for pressures below $10 \mathrm{kPa}$. For the range of pressures considered by NASA for the latest space exploration vehicles $(58.6-68.6 \mathrm{kPa})$, the ignition delay time is reduced by $18-24 \%$ when compared to sea level conditions. In the present experiments the boundary between ignition and no ignition at low pressure is sharper than that observed in the work of Ref. [5]. This may be due to differences in the air flow 


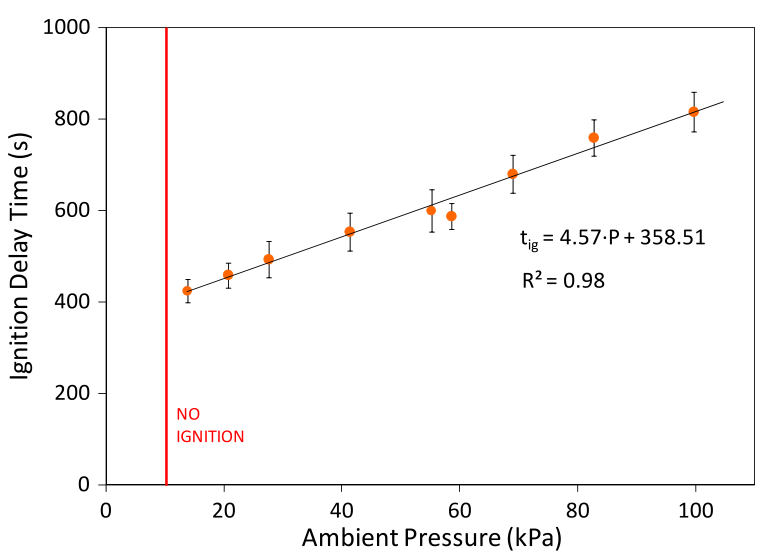

Fig. 5. Ignition delay time vs. pressure.

pattern between the two experimental set-ups in part created by flow perturbations caused by the air gap surrounding the isolated sample holder needed for mass loss measurements and by the a reconfiguration of the tunnel ceiling.

Figure. 6 shows the average total mass loss for the tests performed at different pressures. The total mass loss is calculated as the sample initial mass minus the sample mass at ignition. On average, samples show lower mass loss for ignition under reduced ambient pressure. Although this is not a typically measured quantity, it provides an indication that the total amount of fuel volatiles required for ignition is smaller at lower pressures.

Figure. 7 depicts the measurements of the fuel mass flux at ignition with pressure. This is an important parameter in the fire science literature because it describes the process leading to the ignition of a solid combustible material in a more physically correct manner than other ignition criteria, such as a critical surface temperature $[7,9]$. It is related to the attainment of a flammable mixture near the ignition source (pilot) and often referred to as the critical mass flux, critical mass loss rate, or critical volatile flow rate at ignition [12]. It is seen that the fuel mass flux at ignition also decreases linearly with pressure, although the pressure dependence is weaker than that of the ignition delay time, as shown by the gentle slope of the regression line: $\dot{m}_{0}^{\prime \prime}=0.005 \cdot P+1.48(P$ in $\mathrm{kPa}$ and $\dot{m}_{0}^{\prime \prime}$ in $\left.\mathrm{g} / \mathrm{m}^{2} \mathrm{~s}\right)$. The mass flux at ignition varies by $8-11 \%$ for the range of pressures considered by NASA (58.6-68.6 kPa) when compared to $101 \mathrm{kPa}$. The mass flux at ignition obtained at sea level conditions (Fig. 7, approximately $2.1 \mathrm{~g} / \mathrm{m}^{2} \mathrm{~s}$ for $100 \mathrm{kPa}$ and an incident heat flux of $16 \mathrm{~kW} / \mathrm{m}^{2}$ ) is in good agreement with previously reported values $\left(\dot{m}^{\prime \prime}=1.83-2.05 \mathrm{~g} / \mathrm{m}^{2} \mathrm{~s}\right.$ for heat fluxes

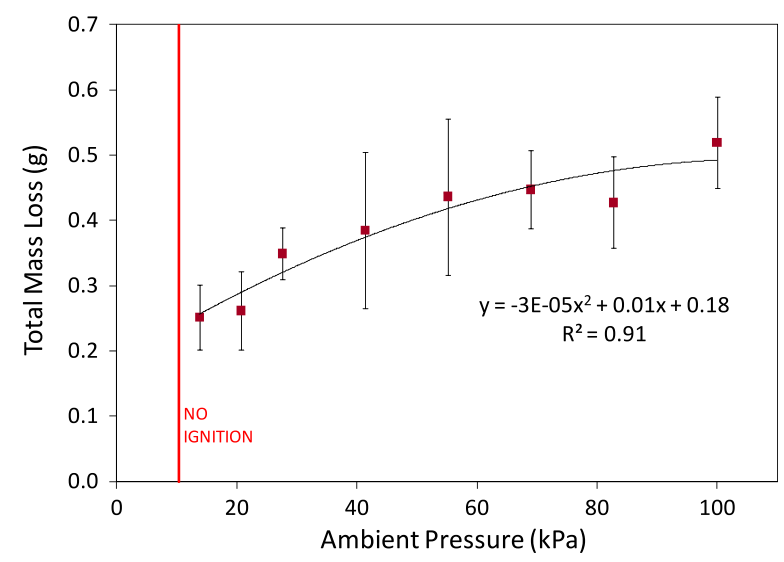

Fig. 6. Total mass loss prior to Ignition vs. pressure.

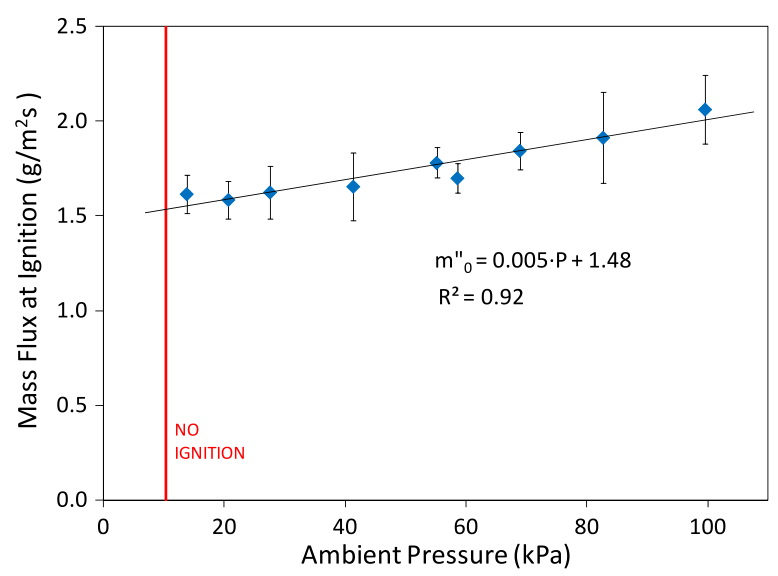

Fig. 7. Mass flux at ignition vs. pressure.

ranging from 13 to $33 \mathrm{~kW} / \mathrm{m}^{2}$ in Ref. [8], $\dot{m}^{\prime \prime}=1.85 \mathrm{~g} / \mathrm{m}^{2} \mathrm{~s}$ at $16 \mathrm{~kW} / \mathrm{m}^{2}$ in Ref. [9]).

\section{Discussion}

The piloted ignition of a thermally irradiated combustible solid can be described as a sequence of three events $[13,14]$ : the solid is heated and pyrolyzed; the pyrolyzate are transported and mixed with the oxidizer to form a combustible mixture; and finally this mixture is ignited by the pilot. As a result, the ignition delay time can be viewed as the sum of three characteristic times: heating time, mixing or transport time and chemical induction time. Depending on the ignition process and ambient conditions, the relative importance of each of these steps might vary. For ignition under low external heat fluxes, such as those presented in this paper, the solid heating time is of the order of hundreds of seconds which significantly larger than the transport/mixing time and the thermal induction time, which are on the order of seconds to milliseconds. Since changes in ambient pressure influence the heating time, they consequently will have a first order effect on the ignition delay time.

\subsection{Solid heating and thermal decomposition}

\subsubsection{Solid heating}

Pressure affects the solid heating time directly through the convective heat losses from the solid surface to the oxidizer flow. For forced flow over a flat plate, the thickness of the thermal boundary layer $\left(\delta_{t}\right)$ depends on the problem parameters in the form $\delta_{t} \sim \frac{x}{\operatorname{Re}^{1 / 2} \mathrm{Pr}^{1 / 3}}$, where the Reynolds number is directly proportional to pressure through the density, resulting in $\delta_{t} \sim 1 / P^{1 / 2}$. Consequently as pressure is reduced, the thickness of the thermal boundary layer increases and the temperature gradients at the solid surface are reduced, resulting in decreased heat losses from the solid to the surrounding gas. An analogous result can be reached by analyzing the effect of pressure on the convection heat transfer coefficient. For forced flow the heat transfer coefficient is of the form $h \sim \operatorname{Re}^{1 / 2} \operatorname{Pr}^{1 / 3}$ resulting in $h \sim P^{1 / 2}$. Similarly, for pure natural convective flow the heat transfer coefficient varies as $h \sim \mathrm{Gr}^{1 / 4} \mathrm{Pr}^{1 / 4}$, where the Grashof number is proportional to the pressure squared, resulting in $h \sim P^{1 / 2}$. For mixed forced and free flow over a flat plate the heat transfer coefficient can be approximated as $h \sim \operatorname{Re}^{1 / 2} \operatorname{Pr}^{1 / 34} \sqrt{1+\frac{\mathrm{Gr}^{3} \mathrm{P}^{3}}{\mathrm{Re}^{2}}}$. Thus, regardless of the flow type (buoyant or forced), simple arguments suggest $h \sim P^{1 / 2}$. Consequently, if pressure is reduced then convective heat losses from the solid fuel to its surroundings will also be reduced, which in turn will result in the solid heating more rapidly and earlier fuel 
pyrolysis. This effect can be clearly seen in the sample surface temperature histories from Fig. 4, where the traces corresponding to lower ambient pressure show higher temperatures resulting from faster heating rates of the PMMA prior to ignition.

Since convective heat losses from the solid to the gas decrease as pressure is reduced, the effect of reduced pressure could be interpreted as an effective increase of the net applied external heat flux. Previous work [7] shows that the surface temperature at ignition increases with the external radiant heat flux, which seems to corroborate the results presented in Fig. 8. This figure shows that the ignition temperature is approximately constant for pressures above $55 \mathrm{kPa}$, with values around $324-330^{\circ} \mathrm{C}$ and it slightly increases with decreasing pressure for pressures below $55 \mathrm{kPa}$, reaching values around $345^{\circ} \mathrm{C}$. The values around $80-100 \mathrm{kPa}$ seem reasonable considering the wide range of ignition temperatures reported in the literature for piloted ignition of PMMA (265 ${ }^{\circ} \mathrm{C}$ in Ref. [7], $310^{\circ} \mathrm{C}$ in Ref. [8], $374^{\circ} \mathrm{C}$ in Ref. [13]).

\subsubsection{Solid thermal decomposition}

Pyrolysis of PMMA is generally described as an Arrhenius type reaction. Because the activation energy for PMMA pyrolysis is large, the first order dependency of solid pyrolysis is on the solid temperature near the surface. Since the surface temperature is higher at lower pressure it can be inferred that the pyrolysis rate would also be higher as pressure is decreased. On the other hand the thickness of the solid thermal layer decreases as the pressure is decreased because ignition occurs sooner. It appears that the former effect is dominant since the experiments of Fig. 4 show an increase in mass loss as the pressure is reduced. Another aspect of the PMMA thermal decomposition process that should be considered is the bubble dynamics that affect the in-depth pyrolysis of the PMMA and the movement of pyrolyzate through the softened condensed phase $[15,16]$. As the PMMA is heated by external thermal radiation, it undergoes a glass transition around $100{ }^{\circ} \mathrm{C}$. As its temperature is increased further, the amorphous component of the polymer continues to soften, the molecules inside the polymer become increasingly mobile, and eventually they depolymerize (unzip), forming gaseous compounds (primarily MMA) which nucleate as bubbles in the softened condensed phase. The resultant gas bubbles diffuse throughout the softened polymer, eventually reaching the surface where they burst, exposing subsurface layers of the polymer to surrounding oxygen. Previous work on the bubble dynamics of PMMA under variable external heat flux and oxygen concentration [15] shows that the mass transfer of pyrolyzate is not only diffusive but bubble induced, and that consequently the gasification rate cannot be simply proportional to surface temperature or to energy input. The results of the present work seem to confirm the previous statement.

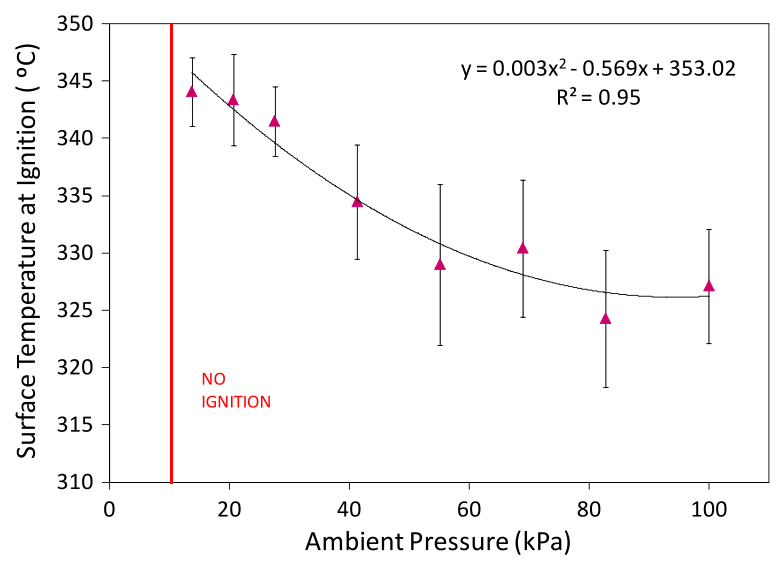

Fig. 8. Surface temperature at ignition vs. pressure.
Plots of mass loss ( $\mathrm{g}$ ) and mass flux $\left(\mathrm{g} / \mathrm{m}^{2} \mathrm{~s}\right)$ as a function of surface temperature for different ambient pressures as those of Figs. 9 and 10 show that they are not function of surface temperature only, at least for pressures lower than $28 \mathrm{kPa}$. This suggests that other processes may participate in the thermal decomposition of the PMMA. In Ref. [15] it is also reported that smaller bubbles occur with increased oxygen concentration and increased radiant flux. The present observation that smaller pyrolyzate bubbles appear at lower pressures is similar to the results of Ref. [14], since decreasing pressure can be thought of as analogous to an increase of the net heat flux into the solid. Furthermore the bubbles add complexity since they alter the optical properties of the polymer sample and consequently its reflectivity and in-depth radiation [15]. These effects are complex and their study beyond the scope of this work.

\subsection{Mass flux at ignition}

The observed reduction in the mass flux at ignition is attributed primarily to the attainment of a flammable mixture conditions near the igniter sooner. This can be explained phenomenologically by the simple fact that as the total pressure is reduced, the oxygen concentration is also reduced, therefore less fuel vapor is needed to reach the lower flammability limit at the pilot. Though the oxidizer flow velocity is the same in all the tests, the oxidizer mass flow rate decreases with pressure because the density is reduced. For Lewis number close to unity the thermal and concentration boundary

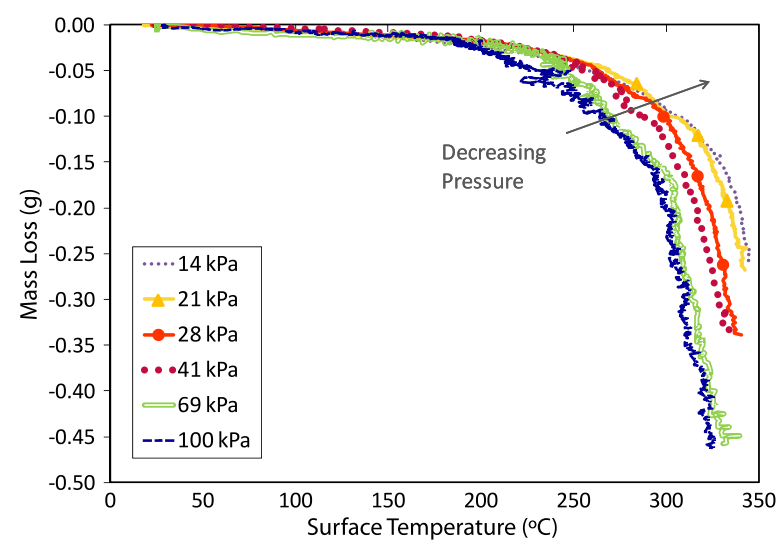

Fig. 9. Mass loss vs. surface temperature.

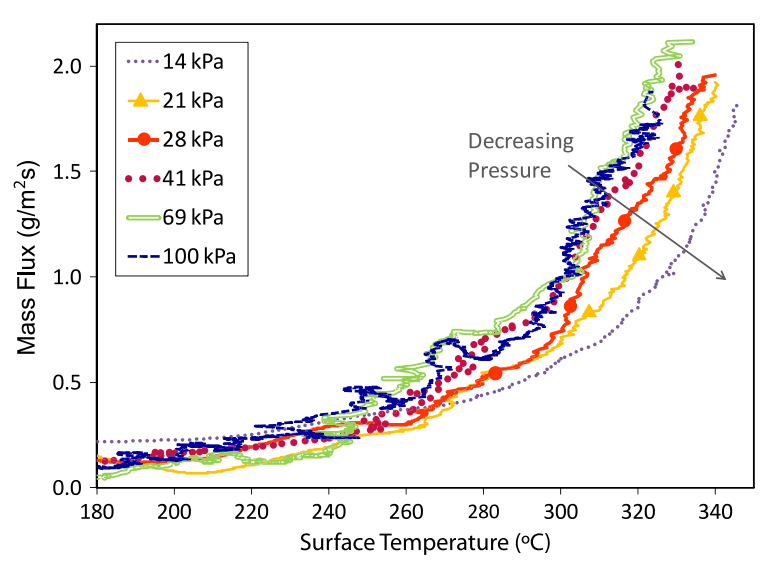

Fig. 10. Mass flux vs. surface temperature. 
layers are equivalent, thus the concentration boundary layer thickness has a pressure dependence proportional to $1 / P^{1 / 2}$. As a result a reduction in pressure leads to a thicker species boundary layer profile which results in lower species gradients at the solid fuel surface. A reduction of the species concentration gradient at the surface implies a reduction of the mass flux at the surface and consequently a reduction of the fuel mass flux at ignition as observed experimentally in Fig. 7. Consequently, the lower flammable limit at the igniter is achieved at lower fuel mass fluxes as the ambient pressure is reduced. This conclusion was also reached in a previous work by the authors [17] where a simple integral boundary layer analysis was used to demonstrate that as the pressure is reduced, a lower fuel mass flux is necessary to reach the lower flammable limit at the igniter. It appears that this is the dominant effect that is responsible for reduction of the critical mass flux at ignition with pressure.

\section{Conclusion}

The present work establishes that a reduction in ambient pressure decreases the ignition delay time and the fuel mass flux at ignition. Reduced pressure reduces both the heat transfer coefficient (leading to faster heating of the solid) and the fuel mass flux necessary to reach the lower flammable limit at the igniter (leading to ignition at a lower fuel mass flux).

Past work has shown that the mass flux at ignition varies with applied heat flux and oxygen concentration. In this work we also show that it varies with ambient pressure. Therefore the critical mass flux at ignition cannot be considered a single value for a given material.

These results indicate that solid combustible materials are easier to ignite in low pressure environments such as those found at high altitude locations or inside under-pressurized compartments such as aircraft and spacecraft. This may represent a higher fire hazard, which may be even more significant if the environment also includes an elevated oxygen concentration.

\section{Acknowledgments}

This work was supported by NASA Grant NNX08BA77A. The authors would like to thank Sara McAllister and David Rich for sharing their valuable experience in the FIST program and their key assistance in setting up the experiments and Chris Ategeka and Danielle Kirchmeyer for their help running the experiments.

\section{References}

[1] FAA Airworthiness Standards: Transport Category Airplanes, 14 CFR, FAR $\S 25.841$ : Pressurized Cabins.

[2] K. Lange, A. Perka, B. Duffield, F. Jeng, Bounding the Spacecraft Design Space for Future Exploration Missions, NASA/CR-2005-213689, NASA Johnson Spaceflight Center, 2005.

[3] J.K. Dai, L.Z. Yang, X.D. Zhou, Y.F. Wang, Y.P. Zhou, Energy Fuels 24 (1) (2010) 609-615.

[4] S. McAllister, C. Fernandez-Pello, D. Urban, G. Ruff, Proc. Combust. Inst. 32 (2) (2009) 2453-2459.

[5] S. McAllister, C. Fernandez-Pello, D. Urban, G. Ruff, Combust. Flame 157 (9) (2010) 1753-1759.

[6] D. Hirsch, J. Williams, S. Harper, H. Beeson, G. Ruff, M. Pedley, Pressure flammability thresholds of selected aerospace materials, in: 40th International Conference on Environmental Systems, AIAA, Barcelona, Spain, July 11-15, 2010.

[7] D.J. Rasbash, D.D. Drysdale, D. Deepak, Fire Safety J. 10 (1) (1986) 1-10

[8] D. Drysdale, H. Thomson, Fire Safety J. 14 (1989) 179-188.

[9] D. Rich, C. Lautenberger, J.L. Torero, J.G. Quintiere, C. Fernandez-Pello, Proc. Combust. Inst. 31 (2) (2007) 2653-2660.

[10] V. Babrauskas, Ignition Handbook, Fire Science Publishers, Issaquah, WA, 2003, pp. 112-113, 246-248.

[11] C. Fernandez-Pello, J.L. Cordova, Combust. Sci. Technol. 156 (2000) 271-289.

[12] D. Drysdale, An Introduction to Fire Dynamics, second ed., John Wiley \& Sons, Ltd., West Sussex, England, 1998. p. 82-85.

[13] J.G. Quintiere, Fundamentals of Fire Phenomena, John Wiley \& Sons, Ltd., West Sussex, England, 2006.

[14] J.G. Quintiere, in: G. Cox (Ed.), Combustion Fundamentals of Fire, Academic Press, San Diego, 1995.

[15] T. Kashiwagi, T.J. Ohlemiller, Proc. Combust. Inst. 19 (1) (1982) 815-823.

[16] K.M. Butler, NIST SP 998, May 2003.

[17] S. Fereres, C. Lautenberger, C. Fernandez-Pello, D.L. Urban, G.A. Ruff, The effect of environmental pressure on the mechanisms controlling the piloted ignition of combustible materials, in: 40th International Conference on Environmental Systems, AIAA, Barcelona, Spain, July 11-15, 2010. 